TITLE:

\title{
Hub port competition and welfare effects of strategic privatization
}

\author{
$\operatorname{AUTHOR}(\mathrm{S})$ :
}

Czerny, Achim; Höffler, Felix; Mun, Se-il

CITATION:

Czerny, Achim ...[et al]. Hub port competition and welfare effects of strategic privatization. Economics of Transportation 2014, 3(3): 211-220

ISSUE DATE:

2014-09

URL:

http://hdl.handle.net/2433/196053

\section{RIGHT:}

(c) 2014 Elsevier Ltd. NOTICE: this is the author's version of a work that was accepted for publication in Economics of Transportation. Changes resulting from the publishing process, such as peer review, editing, corrections, structural formatting, and other quality control mechanisms may not be reflected in this document. Changes may have been made to this work since it was submitted for publication. A definitive version was subsequently published in Economics of Transportation, 3(3), 2014 doi:10.1016/j.ecotra.2014.06.002; この論文は出版社版でありません。引用の際には出版社 版をご確認ご利用ください。; This is not the published version. Please cite only the published version. 


\title{
Hub Port Competition and Welfare Effects of Strategic Privatization
}

\author{
Achim Czerny \\ WHU - Otto Beisheim School of Management \\ Felix Höffler \\ achim.czerny@whu.edu \\ University of Cologne \\ felix.hoeffler@uni-koeln.de \\ Se-il Mun ${ }^{1}$ \\ Graduate School of Economics, Kyoto University, \\ Yoshida Hon-machi, Sakyo-ku, Kyoto 606-8501, Japan \\ mun@econ.kyoto-u.ac.jp
}

June 21, 2014

${ }^{1}$ Corresponding author. 


\begin{abstract}
Private operation of port facilities is becoming increasingly common worldwide. We investigate the effect of port privatization in a setting with two ports located in different countries, each serving their home market but also competing for the transshipment traffic from a third region. Each government chooses whether to privatize its port or to keep port operations public. We show that there exist equilibria in which the two governments choose privatization and the national welfare of each port country is higher relative to a situation where ports are public. This is because privatization is a commitment to increase charges relative to public port charges, which allows for a better exploitation of the third region. For some parameter regions, port countries non-cooperatively choose public port operations, while they would be better off if both ports were private. However, customers of the third region are always better off if port operations are public. We further show that the port country with the smaller home market has a relatively strong incentive to choose private port operation.
\end{abstract}

Keywords: hub port, transport policy competition, infrastructure pricing, privatization JEL Classification: L91, L98, R48 


\section{Introduction}

The hub and spoke system in which hub ports are used to transship cargos from small ships on feeder lines to larger ships on trunk lines is typically adopted in sea transportation. The shares of transshipment traffic at major ports are, for example, $81 \%$ in Singapore, $41 \%$ in Busan, and 30\% in Hong Kong (Shibasaki et al., 2005). Carriers benefit from hub and spoke systems because they are useful in fully exploiting economies in ship sizes. Operating a hub port can also be beneficial for national economies. This is because (i) importers and exporters in the home country's hinterland may enjoy lower transport cost and shorter lead time due to direct connections from/to major origins/destinations and (ii) port profits contribute to the national income. Hub ports typically possess localized monopoly power, yet there still is significant competition between hub ports for transshipment traffic.

Since the 1980s, private operation of port facilities has become increasingly common worldwide, and many governments are considering the privatization of public ports as a policy option to raise the competitive position of their ports (for example, Midoro et al., 2005). One reason frequently discussed is that private port operations may be more cost efficient (Tongzon and Heng, 2005). ${ }^{1}$ However, there may also be strategic reasons for governments to opt for privatization, which may rely on higher port profits as part of national welfare. Our paper tries to explore exactly this effect.

To do so, we consider a two-stage game with two hub ports located in different countries. These ports are used by domestic customers and, in addition, they collect transshipment cargos from feeder ports in a third region. Two hub ports compete for transshipment traffic. At the first stage, each government chooses whether to privatize its port or to keep port operations public, where the government's objective is to maximize the national welfare. At the second stage, ports choose prices (i.e., port charges). A public port chooses the price to maximize national welfare, whereas a private port chooses the price to maximize its profit. We focus on the aspect of privatization of infrastructure such that the manager's objective is shifted from welfare maximization under public operation to profit maximization. ${ }^{2}$ This definition has been shared in the literature of economic analysis on the privatization, as reviewed later. We show that, if the transshipment market is sufficiently large, both ports are privatized in equilibrium and that the national welfare of the port countries increases compared to a situation in which the ports are kept under public operation. Privatization leads to higher port prices (similar to results shown by, e.g., Zhang and Zhang (2003) for the case of airports), which tends to decrease national welfare due to a lower total surplus in the domestic market. Welfare can, however, increase due to higher profits from the transshipment market. For the exploitation of the third region like this, strategic interaction between competing port operators plays a crucial role. Due to the transshipment market,

\footnotetext{
${ }^{1}$ Oum et al. (2008) investigate cost efficiency of airports for various types of operations, including private, public, and mixed regimes.

${ }^{2}$ This could also mean reducing the intensity of regulation of an already privatized firm. The public port operation may be considered as the most extreme form of economic regulation because it involves complete control over the firm's behavior.
} 
port prices become strategic complements. Hence, choosing to privatize at the first stage acts as a commitment to charge high prices at stage two. The other port responds to this by also choosing higher port prices, allowing for a better exploitation of the transshipment market. Privatization can therefore be seen as a form of strategic delegation (Fershtman and Judd, 1987). Our result also suggests that there is too little privatization from the perspective of the two port countries, since each government only accounts for their own increase in profits from this strategic privatization decision. We further show that the smaller a country's domestic market is, the larger the incentive to privatize is, since the port profits become relatively more important under these conditions.

There is growing literature on port competition. Veldman and Buckmann (2003) empirically investigate carrier hub choices between European ports. Park et al. (2006) and Anderson et al. (2008) construct a model that incorporates strategic investment decisions between the competing ports of Shanghai and Busan for transshipment cargoes. De Borger et al. (2008) consider a game with pricing and investment decisions of two congested ports that share the same customers and each have a congested link to a common hinterland. At the first stage, local governments independently and simultaneously choose the port and hinterland capacity, while ports independently and simultaneously choose port charges to maximize profits at the second stage. A recent paper by Wan and Zhang (2013) is closely related to De Borger et al. (2008), however they abstract away from port congestion and consider both the hinterland capacity and road tolls as the first-stage decision variables. Yuen et al. (2008) consider a scenario with one gateway, oligopolistic carriers and a congested hinterland such that the gateway chooses prices to maximize the sum of gateway and carrier profits, and the road charges are chosen to maximize the hinterland's welfare. Xiao, Ng and $\mathrm{Fu}$ (2010) compare the pricing and investment rules for three types of port ownerships: fully privatized, partially privatized, and government controlled. None of the studies mentioned theoretically analyzes the decision whether to privatize ports. ${ }^{3}$

Privatization of infrastructure is the topic of recent papers by Matsumura and Matsushima (2012b) and Mantin (2012) on airports, as well as Matsushima and Takauchi (2014) on seaports. ${ }^{4}$ These papers investigate privatization decisions in a game with a framework and timing similar to ours. They find that privatization may improve national welfare and that governments do indeed have an excessive incentive to privatize since they do not account for the negative externalities imposed on other regions. Our application, and therefore the modeling approach, differs from these contributions. First, in their model the infrastructure services (airport or port services) are complementary, while in our paper port services are substitutes. Second, all demand for infrastructure services stems from one of the two countries, i.e., there is no "third region", whereas in our paper, competition for the third region is a major driver of the results. Third, our results differ from those obtained in the

\footnotetext{
${ }^{3}$ For an overview of the literature on transport policy competition between governments, see De Borger and Proost (2012).

${ }^{4}$ In a recent discussion paper, Lin and Mantin (2013) analyze the welfare effects of airport privatization in a setup that captures domestic as well as international air traffic, while Mantin (2012) and Matsumura and Matsushima (2012b) concentrate on international air traffic.
} 
other studies, since in our model, governments can have an excess incentive to keep ports public. This is due to the fact that there is competition for the third region, which triggers a strategic complementarity in port charges. Ports could better exploit the third region if they coordinated with each other on privatization since this would increase prices in the third region. Since this positive pricing effect on the other region's port profits is not taken into account when deciding on privatization, there is (from the perspective of the two port regions) too small of an incentive to privatize.

Our paper is also related to the literature on mixed oligopolies in which a public firm competes with private firms in the market (e.g., de Fraja and Delbono, 1989). This framework has been expanded to include interactions between governments and competition in international market with two countries (Bárcena-Ruiz and Garzón, 2005; Dadpay and Heywood, 2006; Han and Ogawa, 2008). Whether or not privatization of public firms is welfare increasing in these models depends on how well public firms can offset the market power of private firms and to what extent public firms distort the allocation of output quantities between firms. For the latter, cost structures play an important role. Our focus differs from these studies in the sense that we are not interested in the degree of privatization in an oligopolistic market but rather in the decision whether or not to privatize a natural monopoly (i.e., infrastructure).

Our paper may be considered to be a variant of models in the literature of strategic trade policies (e.g., Brander and Spencer, 1985), in that the government policies affect the competitive position in the international market. Interpreting our model in terms of international trade, countries export port services and compete in the third market. The choice of port charges then corresponds to strategic tax policy. Therefore, our paper complements the literature on strategic trade policy.

This paper is organized as follows. In Section 2, we present the basic model. Section 3 investigates pricing competition between two ports under public and private operation. In Section 4, we discuss port privatization and welfare effects. Section 5 concludes. Proofs are relegated to the Appendix.

\section{The Model}

Suppose that there are two countries $(i=1,2)$, each with a single port, and a third region (which may consist of various countries). We assume the spatial structure as in Figure 1 (similar to Takahashi, 2004) in which the two countries are points; the third region is a set of locations on a continuous linear space between two countries with the length equal to $b .^{5}$ Each location within the third region is represented by a coordinate value, $x \in[0, b]$, whereby the locations of countries 1 and 2 are $x=0$ and $x=b$, respectively.

Figure 1

\footnotetext{
${ }^{5}$ Matsumura and Matsushima (2012a) use a similar model in the context of a delegation game.
} 
In each of the two countries, there is demand for a transport service to some destination in the rest of the world, for which the usage of one of the two ports is necessary. We assume that local demand in each of the two countries uses the country's local port. The demand of the home market for the transport service of port $i$ is given by:

$$
D_{i}^{H}\left(p_{i}\right)=a_{i}-p_{i}
$$

Here, $p_{i}=c_{i}+\tau_{i}$ is the "full price" for a local customer of port $i$, with $c_{i}$ being operational costs of a customer using port $i$ (which might include time cost for cargo handling, line haul cost on the trunk line, etc.) and $\tau_{i}$ being the port charge of port $i$. The customer's operational $\operatorname{cost} c_{i}$ can also be interpreted as an inverse measure of the quality of port $i$; e.g., the shorter handling times, the lower the cost of usage for the port customers will be. In most of the analysis, we will concentrate on situations where in equilibrium $D_{i}^{H}>0$, for $i=1$, which holds if, for instance, $a_{1}$ and $a_{2}$ are sufficiently large.

The two ports also serve as connecting points (hubs) for trade with the third region (cargoes are transshipped between feeder lines and trunk lines). ${ }^{6}$ There are $b$ customers with unit demand and valuation $v$ for the transshipment service, distributed uniformly on this interval. Customers from the third region also need to use one of the two ports and have constant per distance transportation cost from using one of the two hubs of size $t$, in addition to $p_{i}$. We focus on full coverage equilibria, i.e., $v$ is sufficiently large such that all of the customers from the third region always buy the service. The customer who is indifferent between ports 1 and 2 is determined by:

$$
c_{1}+\tau_{1}+t \bar{x}=c_{2}+\tau_{2}+t(b-\bar{x}) \Leftrightarrow \bar{x}=\frac{b t-c_{1}+c_{2}-\tau_{1}+\tau_{2}}{2 t} .
$$

We call the demand of the third region for port services "transshipment" demand; for port services of port $1(2)$, demand is given by $D_{1}^{T}\left(\tau_{1}, \tau_{2}\right)\left(D_{2}^{T}\left(\tau_{1}, \tau_{2}\right)\right)$ :

$$
D_{1}^{T}\left(\tau_{1}, \tau_{2}\right)=\bar{x}, \quad D_{2}^{T}\left(\tau_{1}, \tau_{2}\right)=b-\bar{x}
$$

To ensure that $D_{i}^{T}>0$ in equilibrium, we assume that the transportation cost $t$ is sufficiently high. $^{7}$

There are two ways to operate a port: private and public. Under public operation, the port chooses a port charge to maximize national welfare, which can be written as

$$
W_{i}=\int_{\tau_{i}+c_{i}}^{a_{i}} D_{i}^{H}(x) d x+\tau_{i}\left(D_{i}^{H}+D_{i}^{T}\right)
$$

\footnotetext{
${ }^{6}$ Hub-spoke systems have been studied in the context of networks, i.e., graphs in which nodes are connected by links (e.g., Hendricks, Piccione and Tan, 1999). Our model setting can be interpreted as a specific form of a (simple) network in which each location in the third region (each point on the line) is a node connected directly to two hubs.

${ }^{7}$ Private ports may concentrate on the local market when the market for transships is too competitive. This does not occur when transportation costs $t$ are sufficiently high. See Figure 4 for an illustration of the corresponding critical values of $t$ at which private ports are indifferent between exploitation of the local and the transship markets or the local markets alone.
} 
and consists of the net benefit of local customers (first term) as well as the revenues from port services to local customers and from transshipment demand (second term). Alternatively, a private port chooses a port charge to maximize its profits, $\tau_{i}\left(D_{i}^{H}+D_{i}^{T}\right) .{ }^{8}$

We consider the following two-stage game. First, the governments in both countries simultaneously decide on the mode of port operation (privatization or no privatization). Given this, port charges are determined at stage two in order to maximize the objective function implemented by the government's privatization decision. We solve the game by backward induction.

It is important to stress that ports charge the same to both the home market customers and the customers from the third region. A public port charging different (i.e., lower) prices to home customers would typically violate the rules of the world trade organization (WTO) for free transit. Article 5 of GATT 1994 states: "With respect to all charges, regulations and formalities in connection with transit, each contracting party shall accord to traffic in transit to or from the territory of any other contracting party treatment no less favorable than the treatment accorded to traffic in transit to or from any third country." Private ports that use price discrimination would in many jurisdictions violate non-discrimination obligations. ${ }^{9}$ Hence, in practice, most ports seem to not use price discrimination. ${ }^{10}$

\section{Price competition}

This section takes the modes of operation (that is, whether ports are public or private) as given and considers the individual ports' best responses to the pricing of the rival port. In a further step, equilibrium port charges are derived and discussed.

\subsection{Ports' best responses}

The public port operator chooses a port charge to maximize national welfare $W_{i}$, defined by (3) with respect to $\tau_{i}$. The corresponding optimality condition is

$$
\tau_{i} \frac{\partial D_{i}^{H}}{\partial \tau_{i}}+D_{i}^{T}+\tau_{i} \frac{\partial D_{i}^{T}}{\partial \tau_{i}}=0
$$

An increase in price has a direct negative impact on consumer surplus (which equals to $-D_{i}^{H}$ ) and a direct positive impact on local profits (which equals to $D_{i}^{H}$ ). The two terms cancel

\footnotetext{
${ }^{8}$ Since we assume away the cost for port operation, the normal objective profit maximization is reduced to revenue maximization. If we assumed that port operation cost was proportional to traffic volume, we could interpret $\tau_{i}$ as the port charge net of unit operation cost. In this case, $\tau_{i}\left(D_{i}^{H}+D_{i}^{T}\right)$ becomes the profit.

${ }^{9}$ E.g., for Europe the EU Treaty requires in Art. 102: A dominant firm (for which the ports in our model would typically qualify) must not apply "dissimilar conditions to equivalent transactions with other trading parties...".

${ }^{10}$ However, non-tariff discrimination seems to play a role, in particular by imposing additional costs on foreign transit customers. See, e.g., WTO G/C/W/22 (September 30, 2002), p. 4. It is obvious that in our setup, neither a privately nor publicly operated port would have an incentive to raise a customer's cost.
} 
out when the port maximizes national welfare. So the effect associated with the market for local customers is only the first term, $\tau_{i} \partial D_{i}^{H} / \partial \tau_{i}$, which is negative in sign. The sum of 2 nd and 3rd terms, $D_{i}^{T}+\tau_{i} \partial D_{i}^{T} / \partial \tau_{i}$, is the marginal revenue from transshipment. If there is no transshipment, the welfare maximizing charge is $\tau_{i}=0$. If the port provides transshipment service, the national welfare can be increased by raising the port charge above zero, which is at the expense of lower welfare for local customers.

The private port operator chooses the port charge to maximize the revenue, $\tau_{i}\left(D_{i}^{H}+D_{i}^{T}\right)$, with respect to $\tau_{i}$. The corresponding first-order condition is

$$
D_{i}^{H}+\tau_{i} \frac{\partial D_{i}^{H}}{\partial \tau_{i}}+D_{i}^{T}+\tau_{i} \frac{\partial D_{i}^{T}}{\partial \tau_{i}}=0 .
$$

Since we focus on situations for which $D_{i}^{H}>0$, a comparison of (4) and (5) immediately (and unsurprisingly) shows that, for a given level of the rival's port charge, the public port charge is smaller than the private port charge. ${ }^{11}$ Using our specifications of demand functions (1) and (2), we can explicitly calculate the best response function of a public port $\mathrm{as}^{12}$

$$
T_{i}^{G}\left(\tau_{j}\right)=\frac{\tau_{j}+b t-c_{i}+c_{j}}{2(1+t)}
$$

with slope

$$
\frac{\partial T_{i}^{G}}{\partial \tau_{j}}=\frac{1}{2(1+t)}>0
$$

Likewise, the best response functions of private ports, $T_{i}^{P}\left(\tau_{j}\right)$, and their slopes are

$$
T_{i}^{P}\left(\tau_{j}\right)=\frac{2 a_{i} t+\tau_{j}+b t-(1+2 t) c_{i}+c_{j}}{2(1+2 t)}
$$

and

$$
\frac{\partial T_{i}^{P}}{\partial \tau_{j}}=\frac{1}{2(1+2 t)}>0 .
$$

This establishes that prices of public and private port operators are strategic complements.

Furthermore, the slopes of the public ports' best response functions are steeper than their private counterparts, $\partial T_{i}^{G} / \partial \tau_{j}>\partial T_{i}^{P} / \partial \tau_{j}$. Next, at $\tau_{j}=0$, we have $T_{i}^{P}(0)>T_{i}^{G}(0) .{ }^{13}$ For

\footnotetext{
${ }^{11}$ One can easily check that the second-order conditions for a maximum are satisfied.

${ }^{12}$ The best response function of a public port in (6) is independent of local market size, measured by $a_{i}$. This is not generally the case. In view of (4), the results depend on the slope of the local demand. In our model, the slope is -1 , which is independent of $a_{i}$.
}

${ }^{13}$ Using (6) and (7), we have

$$
T_{i}^{P}(0)-T_{i}^{G}(0)=\frac{t\left(2 a_{i}(1+t)-b t-(1+2 t) c_{i}-c_{j}\right)}{2\left(1+3 t+2 t^{2}\right)} .
$$

When $\tau_{i}=T_{i}^{P}(0)$, we have $D_{i}^{H}=\left(2 a_{i}(1+t)-b t-(1+2 t) c_{i}-c_{j}\right) /(2(1+2 t))$. Applying the condition $D_{i}^{H}>0$, we immediately have $T_{i}^{P}(0)-T_{i}^{G}(0)>0$. 
a given port charge in the other region, the private operator sets a higher port charge than the public operator when $\tau_{j}<\bar{\tau}_{j}$ (which ensures that local demand is strictly positive), where $\bar{\tau}_{j}=2 a_{i}(1+t)-b t-(1+2 t) c_{i}-c_{j}$. Figure 2 illustrates the best response functions of public and private ports.

Figure 2

\subsection{Equilibrium port charges}

There are four combinations of modes of port operation in countries 1 and 2: case $P P$ in which ports in both countries are operated privately; case $G G$ in which ports in both countries are operated publicly; case $P G$ in which the port in country 1 is privately operated, while the port in country 2 is publicly operated; and vice versa for the case $G P$. Let us denote the equilibrium port charges in country $i$ for the four cases by $\tau_{i}^{P P}, \tau_{i}^{G G}, \tau_{i}^{P G}, \tau_{i}^{G P}$, respectively. Explicit expressions for the equilibrium port charges are provided in Appendix A.

We start the analysis of the second stage by investigating the effect of the country size $a_{i}$ and the operational $\operatorname{costs} c_{i}$ on the equilibrium port charges.

Lemma 1 The effect of local market size $a_{i}$ and operational costs $c_{i}$ on equilibrium port charges can be described as:

(i) if $a_{1}<a_{2}$ and $c_{1}=c_{2}$, then $\tau_{1}^{P P}<\tau_{2}^{P P}$ and $\tau_{1}^{G G}=\tau_{2}^{G G}$.

(ii) if $a_{1}=a_{2}$ and $c_{1}<c_{2}$, then $\tau_{1}^{P P}>\tau_{2}^{P P}$ and $\tau_{1}^{G G}>\tau_{2}^{G G}$.

(iii) if $c_{1}=c_{2}$, then $\tau_{1}^{P G}>\tau_{2}^{P G}$ and $\tau_{1}^{G P}<\tau_{2}^{G P}$.

In words: (i) If both ports are privately operated, the port charge in the country with the larger home market is higher, while the size of the home market has no effect on public port charges if both ports are public (the latter hinges upon the assumption that the slope of the home markets' demands are -1 ; see Footnote 12). (ii) With symmetric market sizes, a reduction of operational costs at port $i$ leads to an increase in $i$ 's port charge. This implies that a port with a higher quality of infrastructure (implying lower operational costs for its customers) would charge a higher price in equilibrium. Note that $c_{i}$ also include costs related to shipping on the ocean route. So a difference in $c_{i}$ could represent the relative advantage of ports' locations from/to the trunk line. (iii) If one of the two ports is privatized, given identical operational costs, the port charge of the privately operated port exceeds that of its publicly operated counterpart. This is independent of the size of the country measured by $a_{i}$ : For instance, the private port charge in the smaller country is higher than the public port charge in the larger country.

Next, we examine how the different combinations of modes of port operation affect the level of port charges. We assume that two countries are symmetric, $a_{1}=a_{2}=a_{s}$ and $c_{1}=c_{2}=c_{s}$. This leads to: 
Lemma 2 When the two countries are symmetric, the following relations hold:

$$
\tau_{1}^{P P}>\tau_{1}^{P G}>\tau_{1}^{G P}>\tau_{1}^{G G} \text { and } \tau_{2}^{P P}>\tau_{2}^{G P}>\tau_{2}^{P G}>\tau_{2}^{G G}
$$

The above results state that port charges tend to be higher as port privatization becomes more prevalent. Note that even though the operator is unchanged, the port charge is higher when the rival port is private $\left(\tau_{1}^{P P}>\tau_{1}^{P G}\right.$ and $\tau_{1}^{G P}>\tau_{1}^{G G}$ ) due to the strategic complementarity in pricing decisions. To explain $\tau_{1}^{P G}>\tau_{1}^{G P}$, let us compare two cases of change, i.e., from $\tau_{1}^{G G}$ to $\tau_{1}^{P G}$, and from $\tau_{1}^{G G}$ to $\tau_{1}^{G P}$. The first change reflects the direct effect of port privatization in the home country, which should be larger than the second change through the indirect effect of privatization of the rival port. Based on these results, we illustrate in Figure 3 the best response functions and how the port charges differ in equilibrium for the different modes of operation.

Figure 3

\section{Welfare effects of port privatization}

This section is separated into three parts. The first part derives and discusses equilibrium port operations, while the second part identifies the welfare effects of port privatization. The effect of asymmetries in country sizes on port operations is identified in the third part.

\subsection{Privatization as equilibrium policy choice}

We turn to the first stage of the game, i.e., the selection of modes of port operation by the governments. By doing so, we identify the conditions under which each of the four cases, $P P, P G, G P, G G$ is realized in a subgame perfect equilibrium. Governments choose simultaneously whether to operate their port publicly, or whether to privatize them. Letting $W_{i}^{P P}, W_{i}^{G G}, W_{i}^{P G}, W_{i}^{G P}$ denote the national welfares for the above four cases, which are obtained by substituting equilibrium port charges into (3), the countries' pay-off matrix can be written as:

\begin{tabular}{c|cc} 
& $P$ & $G$ \\
\hline$P$ & $\left(W_{1}^{P P}, W_{2}^{P P}\right)$ & $\left(W_{1}^{P G}, W_{2}^{P G}\right)$ \\
$G$ & $\left(W_{1}^{G P}, W_{2}^{G P}\right)$ & $\left(W_{1}^{G G}, W_{2}^{G G}\right)$
\end{tabular}

We find that for large parameter regions, countries have an incentive to privatize their ports. It is the strategic interaction in the transshipment market which implies that privatization can ever increase national welfare, and that therefore privatization can occur in equilibrium. Port charges are higher under privatization, and they are also strategic complements. Therefore, privatizing at stage one is a valuable pre-commitment to set higher 
port charges at stage two. The best response of the other port (whether private or public) is to also set a higher port charge. Thus, a government can expect much higher prices if it privatizes at stage one. This leads to a much better exploitation of the third region via the transshipment market but to a lower consumer surplus in the national market. If the former outweighs the latter, privatization is welfare increasing and therefore the optimal policy choice.

It is important to stress that the exploitation of the third region is not sufficient to derive this result. The presence of competition, or strategic interaction with the rival country, is essential. To understand this, consider a port that faces no competition. If the port is private, the operator chooses the profit maximizing port charge. On the other hand, the public port operator chooses the national welfare maximizing port charge. In this setting, by definition, national welfare must be higher in the case of the public port. There is no gain from privatization without strategic interaction.

We first derive the equilibrium results for the choice of the mode of operation for the symmetric case, $a_{1}=a_{2}=a_{s}$ and $c_{1}=c_{2}=c_{s}$. To understand the equilibrium outcomes, it is useful to characterize the circumstances under which a country is indifferent between private or public port operations, given the choice of the other country. This depends on the profitability of the transshipment market, determined by $t$, and the size of the home markets $\left(a_{s}\right)$ relative to the size of the transshipment market $(b)$, which we measure by $\widehat{a}_{s}:=2\left(a_{s}-c_{s}\right) / b$. If country 1 decided at stage one to privatize, then country 2 is indifferent with respect to private or public port operation if

$$
\begin{aligned}
W_{2}^{P G}\left(\widehat{a}_{s}, t\right) & =W_{2}^{P P}\left(\widehat{a}_{s}, t\right) \Rightarrow \\
\widehat{a}_{s} & =a_{s}^{P P G P}=\frac{3+4 t(5+4 t(3+2 t(2+t)))}{1+16 t(1+t)^{2}(1+2 t)} .
\end{aligned}
$$

For the case that country 1 chose public port operations, the indifference condition is

$$
\begin{aligned}
W_{2}^{G G}\left(\widehat{a}_{s}, t\right) & =W_{2}^{G P}\left(\widehat{a}_{s}, t\right) \Rightarrow \\
\widehat{a}_{s} & =a_{s}^{P G G G}=\frac{3+4 t(4+t(7+2 t(3+t)))}{2(1+t)(1+2 t)(1+2 t(2+t))}
\end{aligned}
$$

Figure 4 plots these indifference conditions. It illustrates that both are downward sloping for sufficiently low values of $t$, and slightly upward sloping for sufficiently high values of $t$. To see why they can be downward sloping, consider a point on $a_{s}^{P G G G}$. Now, imagine that the importance of the home market shrinks. This implies that, if the port is kept public, port charges remain unchanged (see (6)), but the welfare contribution of the national market becomes less important. Therefore, the government now opts for privatization since this allows for better exploitation of the (now relatively more important) transshipment market. Alternatively, consider again a point of $a_{s}^{P G G G}$ but let the transshipment market become more attractive, i.e., $t$ increases. With such a change, the government may now prefer to keep the port public. The reason is that the higher attractiveness of the transshipment market leads to a steep increase in the private port charge, which (from the perspective of 
national welfare) decreases national consumer surplus too much. A similar reasoning holds for $a_{s}^{P P G P}$.

\section{Figure 4}

Given the two critical values $a_{s}^{P P G P}$ and $a_{s}^{P G G G}$, we can directly identify the subgame perfect privatization decision in Figure 4. We are mainly interested in equilibria in which all markets (both home markets and the transshipment market) are served; therefore, we focus on parameter constellations to the right of the upward sloping line $a_{s}^{H}$ and above $a_{s}^{L} .{ }^{14}$ To the left of $a_{s}^{H}$, the transshipment market is too unattractive, and below $a_{s}^{L}$, the home market is too small to be served. ${ }^{15}$ The line $a_{s}^{P G G G}$ is downward sloping for sufficiently low values of $t$. This downward sloping part reflects that the national market size and the attractiveness of the transshipment market may be considered as "substitutes" for the government since both favor public port operations. Hence, in the top-right area of Figure 4, keeping the ports public is very attractive, independent of the behavior of the other country, and $G G$ is the equilibrium outcome. The opposite holds for low importance of the home market and low attractiveness of the transshipment market, where $P P$ is the equilibrium outcome.

If the home market takes an intermediate size, asymmetric equilibria are possible if $t$ is sufficiently large. If the other country privatized, it is then a best response not to privatize since this would lead to a too strong increase in the port charges. Finally, there are also multiple equilibria possible. If the home market is very important but the transport cost is very small, keeping the port public is also an optimal response, given the large importance of local consumer surplus. However, if the other country had privatized, following suit is optimal: There is a positive gain in terms of better exploiting the transshipment market; but since $t$ is very small, the price increase is small as well.

These findings discussed for Figure 4 are made precise in the following proposition.

Proposition 1 Assume that countries are symmetric and that the transshipment market is sufficiently attractive, $\widehat{a}_{s}<a_{s}^{H}$. (i) For $\widehat{a}_{s} \leq a_{s}^{P G G G}$ and $\widehat{a}_{s} \leq a_{s}^{P P G P}$, the subgame perfect

\footnotetext{
${ }^{14}$ To construct $a_{s}^{H}$, consider the scenario with one public and one private port. Then calculate the claimed equilibrium, which implies that all markets are served. Now calculate the deviation profit that results if the private port were to deviate to serving only its home market. The critical value of $t$ that renders this deviation unprofitable is given by the upward sloping line in Figure 4 and by:

$$
a_{s}^{H}=2 \frac{8 t(1+t)(1+2 t)(3+2 t)+(3+2 t)(3+4 t(3+2 t)) \sqrt{2} \sqrt{t(1+2 t)}}{9+8 t(5+4 t(2+t))}
$$

A similar line can be constructed for the case of two private ports. The critical value of $t$ is to the left of $a_{s}^{H}$. Similar lines do not exist for public ports. A private port abandons the transshipment market to charge higher prices in the home market. If a public port were to fully abandon serving the transshipment market, this would call for marginal cost pricing in the home market. However, with marginal cost pricing, there is always positive transshipment sales.

On the other hand, $a_{s}^{L}=\frac{2 t}{1+2 t}$, which is obtained by solving $q_{i}^{H}=0$. All calculations are available from the authors upon request.

${ }^{15}$ Therefore, below $a_{s}^{L}$ the subgame perfect outcome is $P P$. To the left of $a_{s}^{H}$, our conjecture is that no equilibrium in pure strategies exists.
} 
equilibrium is unique and the outcome is PP. (ii) For $\widehat{a}_{s} \geq a_{s}^{P P G P}$ and $\widehat{a}_{s} \geq a_{s}^{P G G G}$, the subgame perfect equilibrium is unique and the outcome is GG. (iii) For $t$ sufficiently large, $a_{s}^{P P G P}<a_{s}^{P G G G}$. Then, if $\widehat{a}_{s}$ falls in this range, $a_{s}^{P P G P}<\widehat{a}_{s}<a_{s}^{P G G G}$, there are multiple equilibria in that the outcome may be $P G$ or GP. (iv) For low values of $t, a_{s}^{P P G P} \geq a_{s}^{P G G G}$. Then, if $\widehat{a}_{s}$ falls in this range, $a_{s}^{P G G G}<\widehat{a}_{s}<a_{s}^{P P G P}$, there are multiple equilibria in that the outcome may be GG or PP.

\subsection{Welfare effects}

The previous section has shown that privatization can occur as an equilibrium choice of a welfare maximizing government. Obviously, this need not imply that providing governments with the option to privatize must increase total welfare of both countries. To analyze this, we need to compare national welfare levels under $P P$ and $G G, W_{i}^{P P}$ and $W_{i}^{G G}$ :

$$
W_{i}^{P P}-W_{i}^{G G}=\frac{2 t^{2}\left(\left(a_{s}-c_{s}\right)(1+2 t)-b t\right)\left(\frac{b\left(1+4 t+2 t^{2}\right)}{2 t}-\left(a_{s}-c_{s}\right)(1+2 t)\right)}{(1+2 t)^{2}(1+4 t)^{2}} .
$$

Then, we derive the following:

$$
W_{i}^{P P}>W_{i}^{G G} \Longleftrightarrow a_{s}^{L}<\widehat{a}_{s}<a_{s}^{P P G G},
$$

where $a_{s}^{P P G G}=\left(1+4 t+2 t^{2}\right) / t(1+2 t)$. The first inequality is always satisfied if $D_{i}^{H}>0$. Figure 4 plots the curve, $a_{s}^{P P G G}$, which lies above the maximum of $a_{s}^{P P G P}$ and $a_{s}^{P G G G} .{ }^{16}$ In other words, the parameter region for case $P P$ to be the outcome of a subgame perfect equilibrium is a strict subset of the region in which $W_{i}^{P P}>W_{i}^{G G}$ holds. This directly implies:

Proposition 2 Suppose that the two countries are symmetric. (i) Whenever privatization $P P$ is a subgame perfect equilibrium of the game, national welfare is higher in both port countries compared to $G G$, i.e., a situation in which both ports remain public. (ii) If the size of the home market, measured by $\widehat{a}_{s}$, takes on intermediate values in the non-empty range $\left[\max \left\{a_{s}^{P P G P}, a_{s}^{P G G G}\right\}, a_{s}^{P P G G}\right]$, then in equilibrium governments will decide not to privatize, while both countries would be better off by privatizing their ports.

The first part of the proposition implies that providing the governments with the option to privatize, even if they cannot coordinate this decision, increases welfare of both countries. The second part states that their individual incentive to privatize is too small: If the port countries could coordinate, they would do so only in order to privatize the port infrastructure more often.

To understand the first part, i.e., why privatization is beneficial, we take a closer look at the relations between port charges and the national welfare. Differentiating (3) with respect to the rival port charge, $\tau_{j}$, yields

$$
\frac{\partial W_{i}}{\partial \tau_{j}}=\tau_{i} \frac{\partial D_{i}^{T}}{\partial \tau_{j}}>0
$$

\footnotetext{
${ }^{16}$ To see this, calculate $a_{s}^{P P G G}-a_{s}^{P P G P}=\frac{b(1+t)(1+4 t)^{2}(1+8 t(1+t))}{2 t(1+2 t)\left(1+16 t(1+t)^{2} 2(1+2 t)\right)}>0$.
} 
An increase in $\tau_{j}$ induces larger transship demand in port $i\left(\partial D_{i}^{T} / \partial \tau_{j}>0\right)$, thereby increasing the welfare of country $i$.

Based on this result, Figure 5 shows country 1's indifference curves, the locus of combinations of $\left(\tau_{1}, \tau_{2}\right)$ that give the same level of national welfare. These indifference curves are upward sloping for $\tau_{1}>T_{1}^{G}\left(\tau_{2}\right)$ and downward sloping for $\tau_{1}<T_{1}^{G}\left(\tau_{2}\right) .{ }^{17}$ The welfare level of country 1 is larger since the curve lies to the right (see (10)). Suppose that the rival's port charges are given by $\tau_{2}^{P P}$ and $\tau_{2}^{G G}$ under $P P$ and $G G$ in Figure 5 . The best response of country 1 would be $T_{1}^{P}\left(\tau_{2}^{P P}\right)$ and $T_{1}^{G}\left(\tau_{2}^{G G}\right)$, thereby attaining pricing equilibria at points $P$ and $G$ in the figure, respectively. The curves $W_{1}^{P P}$ and $W_{1}^{G G}$ correspond to these equilibria. In the case of Figure 5, the national welfare of country $i$ under $P P$ is larger than that under $G G$ since the curve $W_{1}^{P P}$ lies to the right of $W_{1}^{G G}$. Although the national welfare is not maximized at the point $P$ in response to $\tau_{2}^{P P}$, the point is better than the point $G$ at which the welfare is maximized in response to $\tau_{2}^{G G}$. Privatization of the two ports leads to higher port charges in both countries 1 and 2. In other words, the decision to privatize becomes a commitment to set higher port charges. The two countries enjoy higher welfare at the expense of the third region using transshipment service at one of two ports.

National welfare is not increased by privatization if the size of the local demand (transship demand) is relatively large (small), as suggested by (9). In this case, the contribution of the revenue from transshipment to national welfare is relatively small. The increase in the port charge by privatization therefore does not generate sufficiently large revenues to offset the loss in local customers' welfare in this situation.

\section{Figure 5}

The second part of the Proposition 2 implies that (from the viewpoint of the two port countries) there is an excessive national incentive to keep the ports public. This result can be explained by a simple externality. The decision to privatize has three (direct) welfare effects: (i) It reduces welfare from their own national market, (ii) it increases their own profits from the transshipment market, and (iii) it increases the other countries profits from the transshipment market. Since the individual decision is based only on effects (i) and (ii), the individual incentive to privatize falls short of the joint benefit from doing so.

Figure 4 illustrated that even in the symmetric case, asymmetric equilibria are possible $(P G$ and $G P)$. From the decision of one country to privatize, both port countries benefit compared to a situation in which both ports are kept public. The reason is simple: Assume that in equilibrium, the first country privatizes while the second keeps its port public $(P G)$. The result that the first country is better off compared to $G G$ follows from the fact that $P G$ is a Nash equilibrium. The second country must also be better off since we know from (4) and (5) that privatization leads to an increase in the port charge for country $1, \tau_{1}$. This

\footnotetext{
${ }^{17}$ On the indifference curve, $\left(\partial W_{1} / \partial \tau_{1}\right) d \tau_{1}+\left(\partial W_{1} / \partial \tau_{2}\right) d \tau_{2}=0$ holds. The slope of the curve is $d \tau_{1} / d \tau_{2}=$ - $\left(\partial W_{1} / \partial \tau_{2}\right) /\left(\partial W_{1} / \partial \tau_{1}\right)$. The numerator of the right-hand side is positive based on (10). On the other hand, the denominator depend on the level of the port charge: since $W_{1}$ is maximized at $\tau_{1}=T_{1}^{G}\left(\tau_{2}\right)$, $\partial W_{1} / \partial \tau_{1}$ is positive if $\tau_{1}$ is smaller than $T_{1}^{G}\left(\tau_{2}\right)$ and vice versa.
} 
leaves welfare in the home market of country 2 unaffected but increases demand for port 2's service in the transshipment market, which strictly increases the welfare of country 2. This reasoning is not restricted to the symmetric case.

Proposition 3 If the equilibrium outcome is PG or GP, both port countries are better off compared to the outcome $G G$.

Welfare effects for the third region are straightforward. Welfare for customers in the third region is affected by the sum of the full price and the transportation cost to the hub port. Privatization of the ports raises the port charges and thereby users in the third region are worse off. For the economy as a whole, which consists of two countries and the third region, privatization reduces total welfare. The benefits of privatization for two countries stem from increased port revenues paid by the third region, which cancel out with the loss of the third region. ${ }^{18}$ So the welfare effect of privatization on the economy as a whole is equal to the losses of local consumer surplus in the two countries due to the increasing port charge.

\subsection{Effect of asymmetries between countries}

We next consider a situation in which the two countries are asymmetric in country size. Without loss of generality, we assume that country 2 is larger. The asymmetry is represented by setting $a_{1}=a_{s}-\rho, a_{2}=a_{s}+\rho$, where $\rho \geq 0$, holding constant the total size of the market (defined as $a_{1}+a_{2}+b$ ). Investigating the condition for each case yields the following result.

Proposition 4 Suppose that the home market of country 2 is larger than that of country 1. As asymmetry in country size $(\rho)$ increases,

(i) the case $P G$ is more likely to emerge in equilibrium,

(ii) the cases PP, GG, and GP are less likely to emerge in equilibrium.

The equilibrium with a private port in the smaller country and a public port in the larger country is more likely to emerge when the asymmetry in country size increases. The smaller country has a larger incentive to choose private port operation since the revenue from transshipment makes a relatively large contribution to national welfare. Recall that those ports with a large share of transshipment mentioned in the introduction (Singapore, Hong Kong and Busan) are located in small countries. These ports compete with ports in large countries such as Shenzen, Shanghai in China, etc., and we observe that they are actively introducing private operation and attracting investments by private funds. ${ }^{19}$ Proposition 4 is consistent with the above observations.

\footnotetext{
${ }^{18}$ That revenues cancel out is due to the assumption that the aggregate demand for transship services is perfectly inelastic as long as there is full coverage.

${ }^{19}$ Singapore port had been managed and controlled by the former Port of Singapore Authority until 1997. Following several steps of reorganization, PSA International now operates the port facilities not only in Singapore but also in many ports in Europe, Asia, and the Mid East. It now has commercial objectives and takes decisions on a commercial basis. At the same time, it does remain an entirely government-owned entity with a wholly owned subsidiary of the Government (i.e., Temasek Holdings (Private) Limited), holding
} 


\section{Conclusions}

This paper shows that welfare maximizing governments may choose private operation of their ports in equilibrium and that national welfare under private port operation can be larger than in the case of public port operation. Choosing private port operation can be perceived as a commitment to charge higher prices: Since port charges are strategic complements, the opportunity to commit to higher prices by delegating the pricing decision to a private port operator can be mutually beneficial for port countries. However, a non-cooperative choice of the mode of port operation leads to too little privatization from the perspective of the two port countries since each government does not account for the benefits from privatization to accrue to the other country. Privatization as such is clearly harmful from the viewpoint of the international transshipment market since its only aim is to better exploit the transshipment customers.

The key driver of our results is that the decisions taken by the ports are strategic complements. In our model, this is implied by our choice to model competition between ports as price competition. This fits well in the context of which countries consider the privatization of existing ports with excess capacities. However, it is sometimes suggested that port competition may alternatively be modeled using quantity competition (see, e.g., Wan and Zhang, 2013). We therefore note that for the strategic complementarity to occur, price competition is not a necessary assumption. In fact, port decisions can also be strategic complements when ports compete in quantities. ${ }^{20}$ Intuitively, even with quantity competition, port privatization is a commitment to reduce the transshipment quantity, implying an increase in the transshipment price. The rival port may then react to this by decreasing its quantity when quantities are strategic complements, making port privatization more attractive for each country.

For public policy discussion, our paper implies an additional argument for privatizing

100 percent of the PSA Corporation's shares (Cullinane, Yap and Lam, 2007). A higher degree of private involvement is observed in the port of Hong Kong. Container terminal facilities are all privately owned and operated by four private companies: Modern Terminals Ltd., DPI Terminals, Hongkong International Terminals (HIT) Ltd. and COSCO-HIT Terminals (HK) Ltd. The Hong Kong government is the lessor of land sites to the private terminal operating companies (Song and Cullinane, 2007). In Korea, the Busan Port Authority (BPA), a public and private combined entity, is responsible for developing, managing and operating the Port of Busan and the surrounding areas. BPA rents out the terminals to private operators, including international mega operators such as Hutchison Port Holdings. This scheme was established in 2004 to promote greater private sector participation in port development. Accordingly, New Busan Port is under construction by attracting private investment through various forms of public-private partnerships, such as BTO (Song and Lee, 2007).

${ }^{20}$ One can show that quantities are strategic substitutes in our model with fixed total transship demands, which eliminates the incentives for strategic privatization. However, consider a variation of our model in which transshipment demands are linear in port charges with $D_{i}^{T}=b-\tau_{i}+\gamma \tau_{j},(\gamma>0)$, and domestic demands are given by $D_{i}^{H}=a_{i}-\beta \tau_{i},(\beta>0)$. Furthermore, let ports compete in quantities. The best response functions of public ports are upward sloping when $\beta$ is sufficiently large. Note that quantities can be strategic complements because an increase in the rival's quantities may increase their own domestic supplies and reduce thir own transship supplies, given their own total supply (i.e., the sum of own domestic and transship supplies). Details are available from the authors upon request. 
port infrastructure, in addition to the well understood argument that private operation may imply lower cost than public operation. Whenever there is a significant transshipment demand from outside their own jurisdiction, from a purely national perspective, a national government should consider privatization. This is true even though privatization as such (i.e., with no cost effect) tends to lead to higher prices and therefore lower domestic consumer surplus.

The gain in national welfare arises in the form of larger profits for the port operator. This may be viewed as an undesirable distributional effect within the port country. This distributional effect can, however, easily be avoided if the port operation is privatized in a competitive standard auction. This allows the government to appropriate all port profits. Since auction payments are sunk costs for the operator, none of our results would be affected (which would obviously not be true if one would use a non-lump sum tax to correct for the distributional effects). In addition, for national governments with important port facilities, it could be useful to coordinate their privatization decisions to overcome the problem of the excessive individual incentive to keep the ports public.

From the point of view of the transshipment market, the opposite holds true. Clearly, customers from abroad benefit if a port is left public, since public charges are lower as a result that the operator wants to be soft on national customers. In particular, coordination of port countries to jointly privatize their hubs should be of concern to customers from the transshipment market.

This paper introduces a number of assumptions to simplify the analysis. First, we assume that perfect competition persists in the carrier market, which may not be compatible with the presence of mega-carriers observed in reality. Second, we ignore scale economies in port operation, which is a driving force behind the adoption of hub-spoke system. To incorporate this aspect, we should explicitly formulate the benefit of using the large scale port that many other users use. It would be useful to examine the effect of carrier market power and scale economies on the consequences of transshipment routes and port competition, as well as the resulting implications on privatization. ${ }^{21}$ Third, we recognize that port privatization may accompany regulation to control market power of the private operator, as in the case of airports. We should look at the commonalities and differences in the organizational structure of ports and airports in considering how to design the regulatory schemes suitable for ports. In doing so, it is essential to take into account the asymmetric information between the operator and the government, as well as the interaction among different stakeholders. Finally, it would be beneficial to consider some practical aspects in port development such as, e.g., investment in port facilities; intra-port competition in which two or more different terminal operators provide the service within the same port; or the behavior of mega-terminal operators serving at many different ports in the world.

\footnotetext{
${ }^{21}$ Czerny et al. (2012) analyze the relationship between route choices and scale economies in the context of airline alliances and mergers. The framework developed by Mori and Nishikimi (2002) may also be useful for the analysis of these types of problems.
} 


\section{Appendix A: Equilibrium port charges}

Case $P P$ : Equilibrium port charges in the case $P P$ is the solution for the system of equations, $\left\{\tau_{1}^{P P}=T_{1}^{P}\left(\tau_{2}^{P P}\right), \tau_{2}^{P P}=T_{2}^{P}\left(\tau_{1}^{P P}\right)\right\}$. Using $(7)$, we have

$$
\begin{aligned}
\tau_{1}^{P P} & =\frac{4 a_{1} t(2 t+1)+2 a_{2} t+b t(4 t+3)-c_{1}(1+8 t(1+t))+c_{2}(1+2 t)}{(4 t+1)(4 t+3)} \\
\tau_{2}^{P P} & =\frac{4 a_{2} t(2 t+1)+2 a_{1} t+b t(4 t+3)+c_{1}(1+2 t)-c_{2}(1+8 t(1+t))}{(4 t+1)(4 t+3)} .
\end{aligned}
$$

Case GG:

$$
\begin{aligned}
\tau_{1}^{G G} & =\frac{b t(2 t+3)-\left(c_{1}-c_{2}\right)(2 t+1)}{4 t(t+2)+3} \\
\tau_{2}^{G G} & =\frac{b t(2 t+3)-\left(c_{2}-c_{1}\right)(2 t+1)}{4 t(t+2)+3}
\end{aligned}
$$

Case $P G$ :

$$
\begin{aligned}
\tau_{1}^{P G} & =\frac{4 a_{1} t(t+1)+b t(2 t+3)-c_{1}\left(4 t^{2}+6 t+1\right)+c_{2}(2 t+1)}{4 t(2 t+3)+3} \\
\tau_{2}^{P G} & =\frac{2 t\left(a_{1}+c_{1}-2 c_{2}\right)+b t(4 t+3)+c_{1}-c_{2}}{4 t(2 t+3)+3}
\end{aligned}
$$

Case GP:

$$
\begin{aligned}
\tau_{1}^{G P} & =\frac{2 t\left(a_{2}-2 c_{1}+c_{2}\right)+b t(4 t+3)-c_{1}+c_{2}}{4 t(2 t+3)+3} \\
\tau_{2}^{G P} & =\frac{4 a_{2} t(t+1)+b t(2 t+3)-c_{2}\left(4 t^{2}+6 t+1\right)+c_{1}(2 t+1)}{4 t(2 t+3)+3}
\end{aligned}
$$

\section{Appendix B: Proofs}

\section{Lemma 1}

Using (A1)-(A4) in the Appendix A, we have

$$
\begin{aligned}
\tau_{1}^{P P}-\tau_{2}^{P P} & =\frac{2\left(\left(a_{1}-a_{2}\right) t-\left(c_{1}-c_{2}\right)(t+1)\right)}{4 t+3} \\
\tau_{1}^{G G}-\tau_{2}^{G G} & =\frac{2\left(c_{2}-c_{1}\right)(2 t+1)}{4 t(t+2)+3} \\
\tau_{1}^{P G}-\tau_{2}^{P G} & =\frac{2\left(a_{1}(2 t+1) t-b t^{2}-c_{1}\left(2 t^{2}+4 t+1\right)+3 c_{2} t+c_{2}\right)}{8 t^{2}+12 t+3}
\end{aligned}
$$


Part (i) can be immediately shown by setting $c_{1}=c_{2}$ and $a_{1}<a_{2}$ in (B1) and (B2). Part (ii) can be shown in a similar way. To establish part (iii), note that $c_{1}=c_{2}$ implies that the numerator of (B3) becomes $2 t\left(\left(a_{1}-c_{1}\right)(2 t+1)-b t\right)$, which is positive as long as $D_{1}^{H}>0$.

\section{Lemma 2}

Substituting $a_{1}=a_{2}=a_{s}$ and $c_{1}=c_{2}=c_{s}$ into (A1a)-(A4a) yields:

$$
\begin{aligned}
\tau_{1}^{P P}-\tau_{1}^{P G} & =\frac{2 t\left(\left(a_{s}-c_{s}\right)(1+2 t)-b t\right)}{(1+4 t)(3+4 t(3+2 t))}, \\
\tau_{1}^{P G}-\tau_{1}^{G P} & =\frac{2 t\left(\left(a_{s}-c_{s}\right)(1+2 t)-b t\right)}{3+4 t(3+2 t)}, \\
\tau_{1}^{G P}-\tau_{1}^{G G} & =\frac{2 t\left(\left(a_{s}-c_{s}\right)(1+2 t)-b t\right)}{(1+2 t)(3+4 t(3+2 t))} .
\end{aligned}
$$

It turns out that the signs of the right-hand sides of the above equations all depend on that of $\left(a_{s}-c_{s}\right)(1+2 t)-b t$. To determine the sign, we again use the condition $D_{i}^{H}>0$. Substituting $\tau_{i}^{P P}, \tau_{i}^{P G}, \tau_{i}^{G P}$ and $\tau_{i}^{G G}$ in the symmetric case for $D_{i}^{H}$, we see that $D_{i}^{H}>0$ is equivalent to $\left(a_{s}-c_{s}\right)(1+2 t)-b t>0$. Applying this inequality to the one above, we have $\tau_{1}^{G G}<\tau_{1}^{G P}<$ $\tau_{1}^{P G}<\tau_{1}^{P P}$. Since the two countries are symmetric, $\tau_{1}^{P P}=\tau_{2}^{P P}, \tau_{1}^{G G}=\tau_{2}^{G G}, \tau_{1}^{P G}=\tau_{2}^{G P}$ and $\tau_{1}^{G P}=\tau_{2}^{P G}$. This implies that the inequality for country 2 holds.

\section{Proposition 1}

Case PP: When two countries are symmetric, $W_{1}^{P P}=W_{2}^{P P}$ and $W_{1}^{G P}=W_{2}^{P G}$ hold true. The conditions, $W_{1}^{P P}>W_{1}^{G P}$ and $W_{2}^{P P}>W_{2}^{P G}$ are therefore reduced to $W_{1}^{P P}>W_{1}^{G P}$, which can be rewritten as (recall the definition $\left.\widehat{a}_{s}:=2\left(a_{s}-c_{s}\right) / b\right)$ :

$$
a_{s}^{L}<\widehat{a}_{s}<a_{s}^{P P G P}, \text { where } a_{s}^{L}=\frac{2 t}{(1+2 t)} \text { and } a_{s}^{P P G P}=\frac{3+4 t(5+4 t(3+2 t(2+t)))}{1+16 t(1+t)^{2}(1+2 t)} .
$$

Note that the condition above is obtained by supposing $D_{i}^{H}>0$, which is equivalent to $a_{s}^{L}<\widehat{a}_{s}$. If $\widehat{a}_{s} \leq a_{s}^{L}, D_{i}^{H}=0$, and the national welfare is reduced to the revenue from the transship market. In this case, the national welfare maximization is equivalent to revenue maximization. This situation is also regarded as private operation. So the condition for the case PP is simply $\widehat{a}_{s}<a_{s}^{P P G P}$.

Case $G G$ : The condition for this case is $W_{1}^{G G}>W_{1}^{P G}$. In the same manner as above, we have the following condition:

$$
a_{s}^{P G G G}<\widehat{a}_{s}, \text { where } a_{s}^{P G G G}=\frac{3+4 t(4+t(7+2 t(3+t)))}{2(1+t)(1+2 t)(1+2 t(2+t))} .
$$

Case $P G$ or $G P$ : The conditions for this case are $W_{1}^{P P}<W_{1}^{G P}$ and $W_{1}^{P G}>W_{1}^{G G}$, which are equivalent to:

$$
a_{s}^{P P G P}<\widehat{a}_{s}<a_{s}^{P G G G} .
$$




\section{Proposition 3}

This proposition is proved by showing that $W_{1}^{P G}>W_{1}^{G G}$ and $W_{2}^{P G}>W_{2}^{G G}$ hold when case $P G$ emerges in equilibrium. The first inequality is an equilibrium condition for case $P G$. For country $2, W_{2}^{P G}>W_{2}^{G G}$ is equivalent to $a_{s}^{L}<\widehat{a}_{s}$, which is satisfied when the condition $W_{1}^{P G}>W_{1}^{G G}$ holds (see proof of Proposition 1 above).

\section{Proposition 4}

First, we derive the conditions for each case to emerge in equilibrium.

Case PP: The conditions $W_{1}^{P P}>W_{1}^{G P}$ and $W_{2}^{P P}>W_{2}^{P G}$ are equivalent to $a_{1}^{L}<\widehat{a}_{s}<$ $a_{1}^{P P G P}$ and $a_{2}^{L}<\widehat{a}_{s}<a_{2}^{P P P G}$,respectively, where

$$
\begin{aligned}
a_{1}^{L}= & 2 \frac{t(3+4 t)+\left(3+14 t+8 t^{2}\right) \frac{\rho}{b}}{3+10 t+8 t^{2}} \\
a_{1}^{P P G P}= & \frac{(4 t+3)(4 t(4 t(2 t(t+2)+3)+5)+3)}{(4 t+3)\left(16 t(2 t+1)(t+1)^{2}+1\right)} \\
& +\frac{2(4 t+1)(8 t(2 t(t(2 t+7)+8)+7)+9) \frac{\rho}{b}}{(4 t+3)\left(16 t(2 t+1)(t+1)^{2}+1\right)} \\
a_{2}^{L}= & 2 \frac{t(3+4 t)-\left(3+14 t+8 t^{2}\right) \frac{\rho}{b}}{3+10 t+8 t^{2}} \\
a_{2}^{P P P G}= & \frac{(4 t+3)(4 t(4 t(2 t(t+2)+3)+5)+3)}{(4 t+3)\left(16 t(2 t+1)(t+1)^{2}+1\right)} \\
& -\frac{2(4 t+1)(8 t(2 t(t(2 t+7)+8)+7)+9) \frac{\rho}{b}}{(4 t+3)\left(16 t(2 t+1)(t+1)^{2}+1\right)} .
\end{aligned}
$$

It is easily shown that $a_{2}^{L}<a_{1}^{L}$ and $a_{2}^{P P P G}<a_{1}^{P P G P}$ hold true, thereby the above conditions are reduced to $a_{1}^{L}<\widehat{a}_{s}<a_{2}^{P P P G}$.

Case $G G: W_{1}^{G G}>W_{1}^{P G}$ and $W_{2}^{G G}>W_{2}^{G P}$ are rewritten as $a_{1}^{P G G G}<\widehat{a}_{s}$ and $a_{2}^{G P G G}<\widehat{a}_{s}$, respectively, where

$$
\begin{aligned}
& a_{1}^{P G G G}=2 \frac{(4 t(t(2 t(t+3)+7)+4)+3)}{4(t+1)(2 t+1)(2 t(t+2)+1)}+2 \frac{\rho}{b} \\
& a_{2}^{G P G G}=2 \frac{(4 t(t(2 t(t+3)+7)+4)+3)}{4(t+1)(2 t+1)(2 t(t+2)+1)}-2 \frac{\rho}{b} .
\end{aligned}
$$

Since $a_{2}^{G P G G}<a_{1}^{P G G G}$ hold, the above conditions are reduced to $a_{1}^{P G G G}<\widehat{a}_{s}$.

Case $P G: W_{1}^{P G}>W_{1}^{G G}$ and $W_{2}^{P G}>W_{2}^{P P}$ are rewritten as $a_{s}^{L}+2 \rho / b<\widehat{a}_{s}<a_{1}^{P G G G}$ and $a_{2}^{P P P G}<\widehat{a}_{s}$, respectively, and are reduced to $a_{2}^{P P P G}<\widehat{a}_{s}<a_{1}^{P G G G}$. Equilibrium of case $P G$ does not exist when $a_{2}^{P P P G}>a_{1}^{P G G G}$. 
Case $G P$ : $W_{1}^{G P}>W_{1}^{P P}$ and $W_{2}^{G P}>W_{2}^{G G}$ are rewritten as $a_{1}^{P P G P}<\widehat{a}_{s}$ and $a_{s}^{L}-2 \rho / b<$ $\widehat{a}_{s}<a_{2}^{G P G G}$, respectively, and are reduced to $a_{1}^{P P G P}<\widehat{a}_{s}<a_{2}^{G P G G}$. Equilibrium of case $G P$ does not exist when $a_{1}^{P P G P}>a_{2}^{G P G G}$.

(i) From (B8), the upper bound of the region of case $P G, a_{1}^{P G G G}$, is increasing with $\rho$, while the lower bound, $a_{2}^{P P P G}$, is decreasing with $\rho$ from (B7). Thus, the parameter range of $P G$ is expanded by the increase in the size difference.

(ii) For the case $P P, a_{1}^{L}<\widehat{a}_{s}$ should hold from the condition $D_{i}^{H}>0$. The region of the case $P P$ is reduced by increasing the size difference since $a_{2}^{P P P G}$ is decreasing with $\rho$. Likewise, the region of the case $G G$ is reduced since $a_{1}^{P G G G}$ is increasing in $\rho$. For the case $G P$, the range $a_{2}^{G P G G}-a_{1}^{P P G P}$ is decreasing in $\rho$.

\section{Acknowledgments}

An earlier version of this paper was presented at the Applied Regional Science Conference 2011 in Toyama (Japan) and the ITEA Conference (Kuhmo-Nectar) 2012 held in Berlin (Germany). We would like to thank conference participants and Takaaki Takahashi, Noriaki Matsushima, Yoshitsugu Kanemoto, and Sergio Jara-Diaz for their helpful comments and suggestions. We are most grateful to the editor (Erik Verhoef) and two anonymous referees for their suggestions, which were very helpful in improving the paper. This research was partially supported by the Ministry of Education, Culture, Sports, Science and Technology (MEXT), Grant-in-Aid for Scientic Research (No. 25380294).

\section{References}

[1] Anderson, C. M., Park, Y.-A., Chang, Y.-T., Yang, C.-H., Lee, T.-W. and Luo, M., 2008, A game-theoretic analysis of competition among container port hubs: the case of Busan and Shanghai, Maritime Policy \& Management 35, 5-26.

[2] Bárcena-Ruiz, Juan Carlos and María Begona Garzón, 2005, International Trade and Strategic Privatization, Review of Development Economics 9, 502-513.

[3] Brander, J. A. \& Spencer, B. J., 1985, Export subsidies and international market share rivalry, Journal of International Economics 18, 83-100.

[4] Cullinane, K., Wei Yim Yap, Jasmine S.L. Lam, 2007, The Port of Singapore and its Governance Structure, in: Mary R. Brooks, Kevin Cullinane (eds.), Devolution, Port Governance and Port Performance, Research in Transportation Economics 17, 285-310.

[5] Czerny, A. I., Jost, P.-J. and Mantin, B., 2012, Route choices and the social evaluation of airline mergers and alliances, unpublished manuscript. 
[6] Dadpay, Ali, and John S. Heywood, 2006, Mixed oligopoly in a single international market, Australian Economic Papers 45, 269-280.

[7] de Fraja, G. and Delbono, F., 1989, Alternative Strategies of a Public Enterprise in Oligopoly, Oxford Economic Papers 41, 302-311.

[8] De Borger, B. and Proost, S., 2012, Transport policy competition between governments: A selective survey of the literature, Economics of Transportation 1, 35-48.

[9] De Borger, B., Proost, S. and Van Dender, K., 2008, Private port pricing and public investment in port and hinterland capacity, Journal of Transport Economics and Policy $42,527-561$

[10] Fershtman, C. and Judd, K. L., 1987, Equilibrium incentives in oligopoly, American Economic Review 77, 927-940.

[11] Han, L., and Ogawa, H., 2008, Economic Integration and Strategic Privatization in an International Mixed Oligopoly, FinanzArchiv / Public Finance Analysis 64, 352-363.

[12] Hendricks, K., Piccione, M. and Tan, G., 1999, Equilibria in Networks, Econometrica $67,1407-1434$.

[13] Lin, M. H. and Mantin, B., 2013, Airport privatization in international inter-hub and spoke networks. Available at http://papers.ssrn.com/sol3/papers.cfm?abstract_id=2361832.

[14] Mantin, B., 2012, Airport complementarity: Private vs. Government Ownership and Welfare Gravitation, Transportation Research Part B 46, 381-388.

[15] Matsumura,T., Matsushima, N., 2012a, Locating outside a linear city can benefit consumers, Journal of Regional Science 52, 420-432.

[16] Matsumura, T. and Matsushima, N., 2012b, Airport privatization and international competition, Japanese Economic Review 63, 431-450.

[17] Matsushima, N. and Takauchi, K., 2014, Port Privatization in an International Oligopoly, in Press, Transportation Research Part B.

[18] Midoro, R., Musso, R. and Parola, F., 2005, Maritime liner shipping and the stevedoring industry: market structure and competition strategies, Maritime Policy $\&$ Management $32,89-106$.

[19] Mori, T. and Nishikimi, K., 2002, Economies of transport density and industrial agglomeration, Regional Science and Urban Economics 32, 167-200.

[20] Oum, T.H., Yan, J. and Yu, C., 2008, Ownership forms matter for airport efficiency: A stochastic frontier investigation of worldwide airports, Journal of Urban Economics 64, 422-435. 
[21] Park, Y-A., C.M. Anderson, Y-S. Choi, 2006, A Strategic Model of Competition among Container Ports in Northeast Asia. Final Report, Korea-America Joint Marine Policy Research Center.

[22] Shibasaki, R., Watanabe, T., Kadono, T. and Kannami, Y., 2005, Estimation Methodology and Results on International Maritime Container OD Cargo Volume mainly focused on East Asian Area, Research Report of NLIM No.25 (in Japanese).

[23] Song, Dong-Wook, Kevin Cullinane, 2007, Port Governance in Hong Kong, in: Mary R. Brooks, Kevin Cullinane (eds.), Devolution, Port Governance and Port Performance, Research in Transportation Economics 17, 311-329

[24] Song, Dong-Wook, Lee, Sung-Woo, 2007, Port Governance in Korea, in: Mary R. Brooks, Kevin Cullinane (eds.), Devolution, Port Governance and Port Performance, Research in Transportation Economics 17, 357-375

[25] Takahashi, T., 2004, Spatial Competition of Governments in the Investment of Public Facilities, Regional Science and Urban Economics 34, 455-488.

[26] Tongzon, J. and Heng, W., 2005, Port privatization, efficiency and competitiveness: Some empirical evidence from container ports (terminals), Transportation Research Part A 39, 405-424.

[27] Veldman, S. J., Buckmann, E. H., 2003, A model on container port competition: An application for the West European container hub-ports, Maritime Economics and Logistics $5,3-22$.

[28] Wan, Y. and Zhang, A., 2013, Urban Road Congestion and Seaport Competition, Journal of Transport Economics and Policy 47, 55-70.

[29] Xiao, Y., Ng, A. K. and Fu, X., 2010, The Impacts of Ownership Structure and Competition on Port Capacity Investments and Pricing: An Economic Analysis, Proceedings of the International Forum on Shipping, Ports and Airports (IFSPA) 2010 - Integrated Transportation Logistics: From Low Cost to High Responsibility, 15-18 October 2010, Chengdu.

[30] Yuen, A., Basso, L. and Zhang, A., 2008, Effects of Gateway Congestion Pricing on Optimal Road Pricing and Hinterland, Journal of Transport Economics and Policy 42, 495-526.

[31] Zhang, A. and Zhang, Y., 2003, Airport charges and capacity expansion: effects of concessions and privatization, Journal of Urban Economics 53, 54-75. 


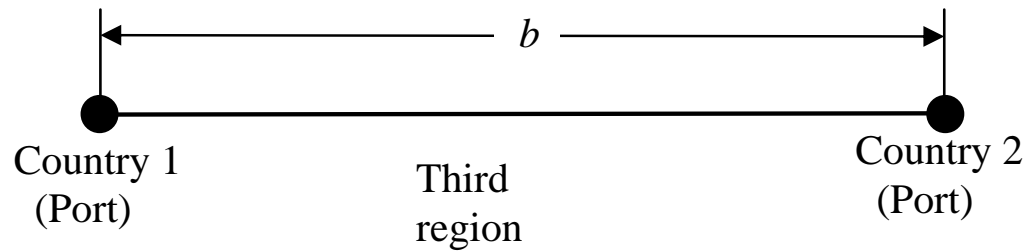

Figure 1 Spatial structure of the economy

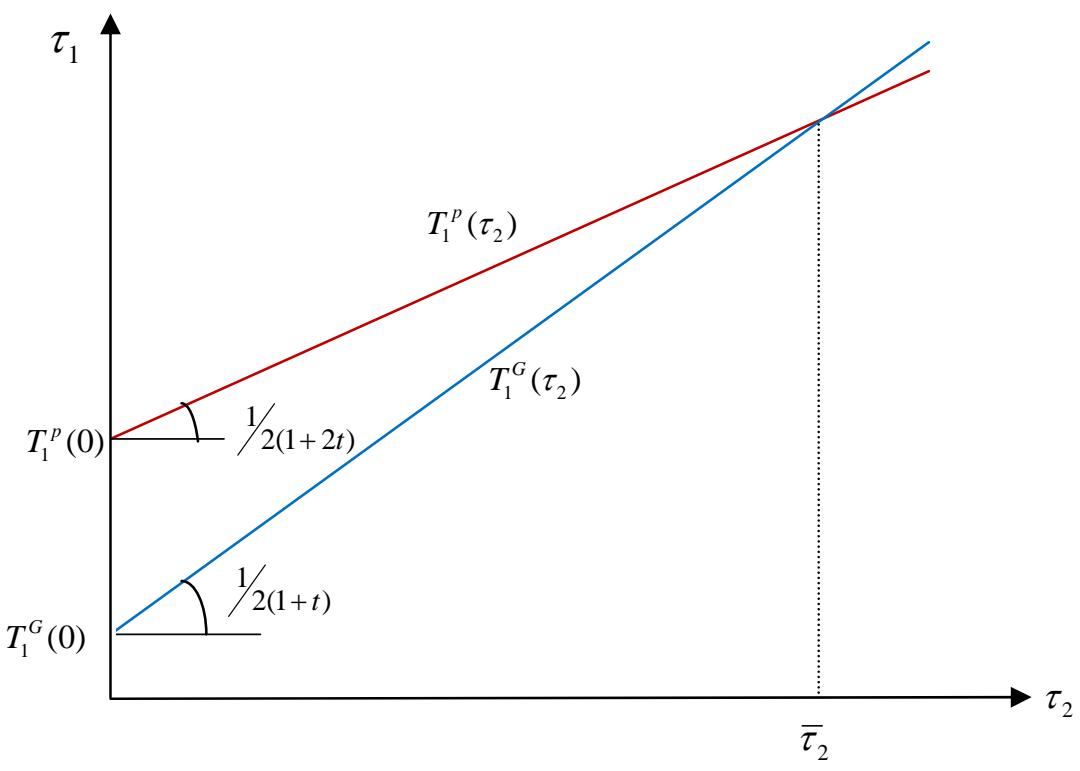

Figure 2 Best response functions 


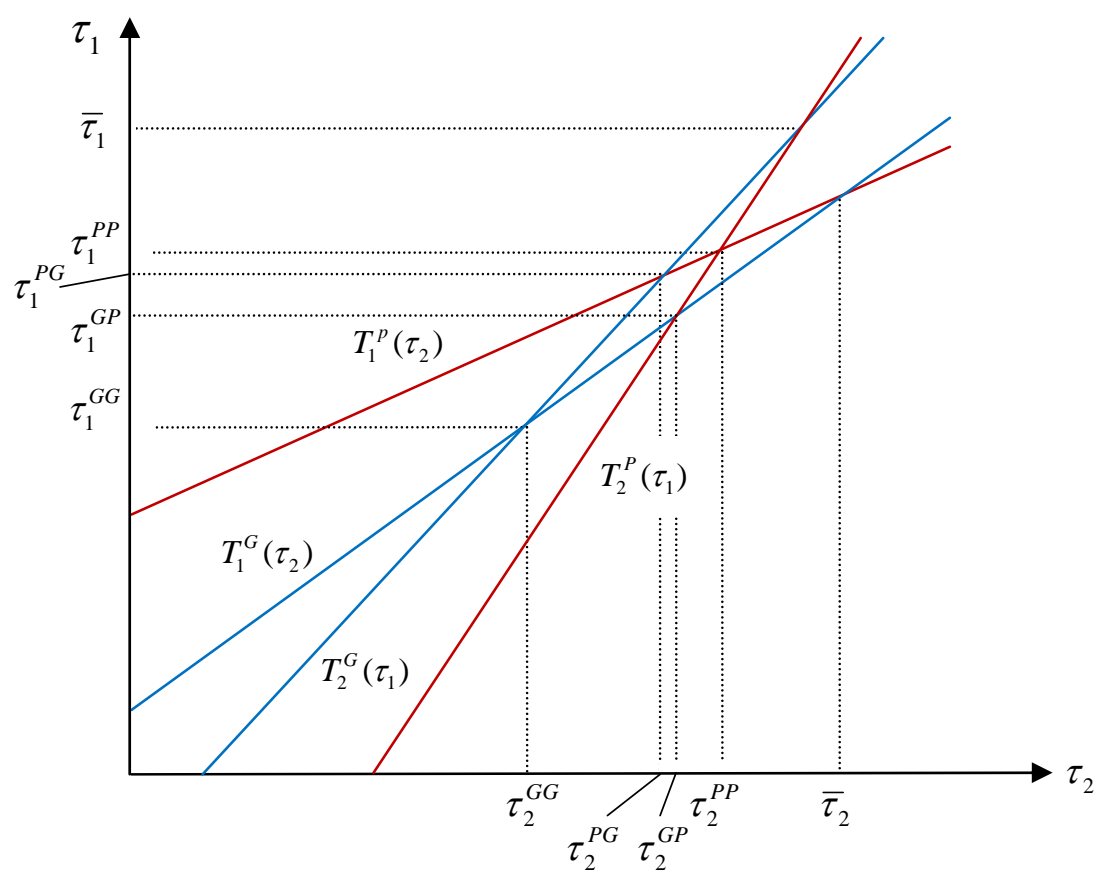

Figure 3 Equilibrium port charges

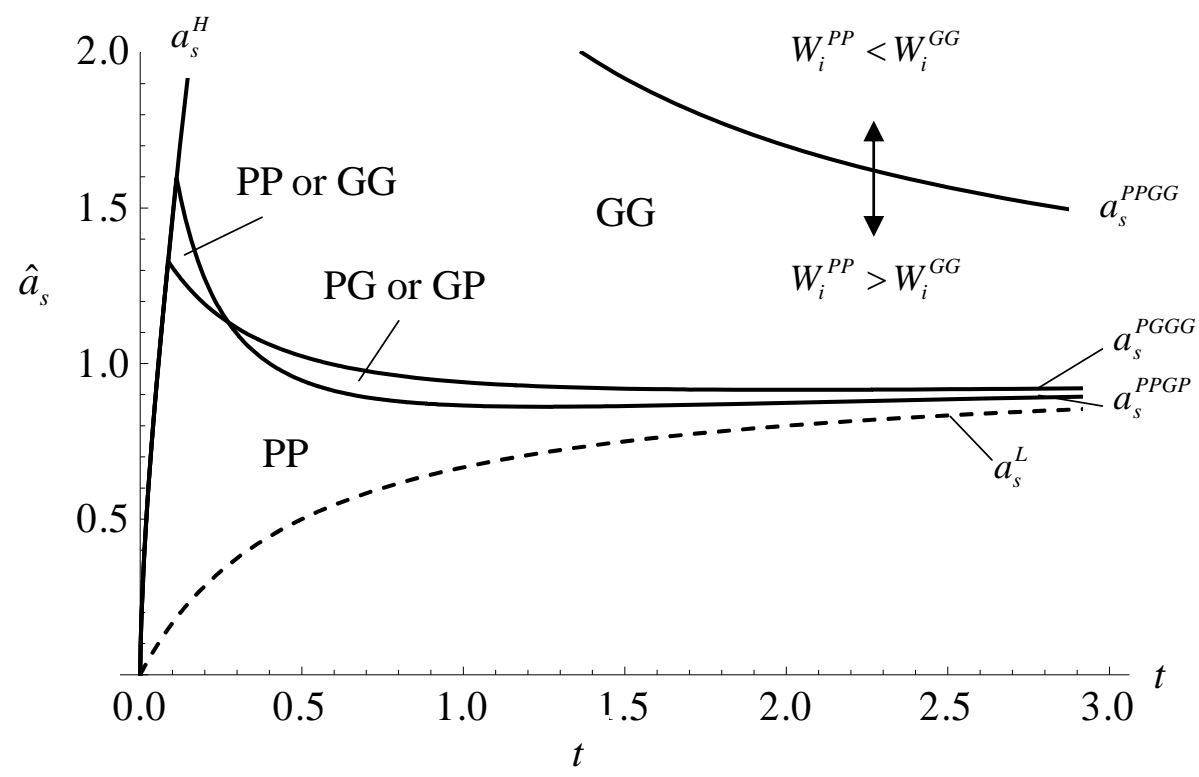

Figure 4 Parameters and equilibrium policy choice 


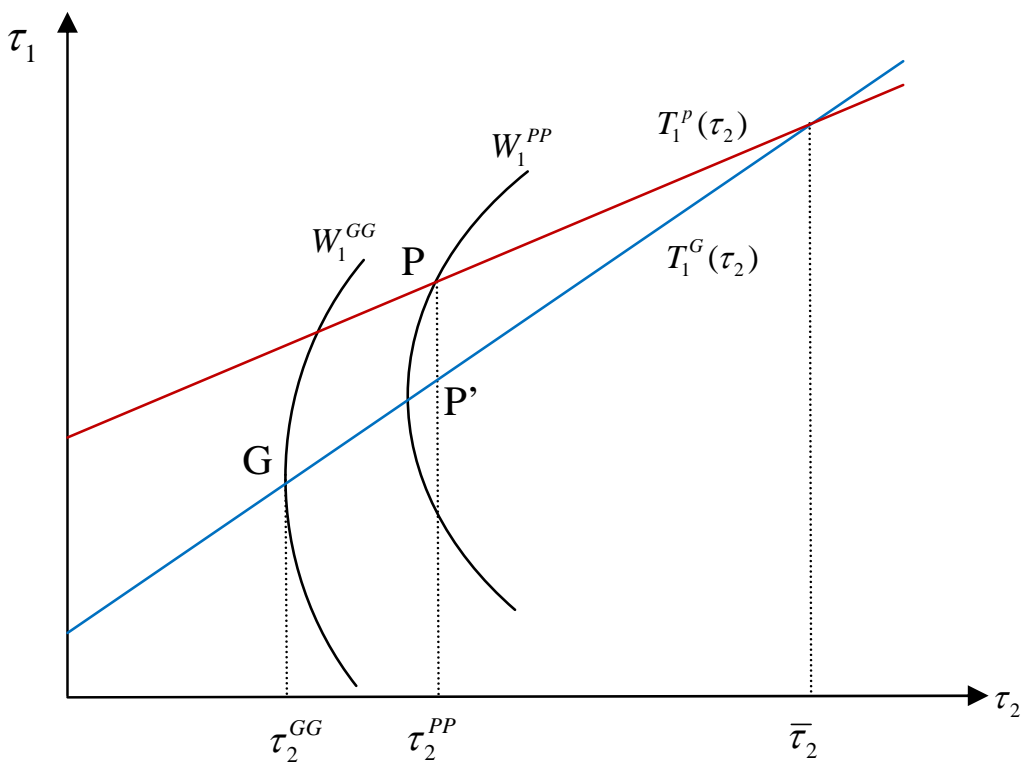

Figure 5 Equilibrium port charges and national welfare 